\title{
A DECORRÊNCIA DO USO DO ÁLCOOL EM PACIENTES QUE SUBMETERAM À CIRURGIA BARIÁTRICA.
}

\author{
Daniela de Lima Porto ${ }^{1}$ \\ Gilmar Antoniassi Júnior ${ }^{2}$
}

\section{RESUMO}

INTRODUÇÃO: O presente estudo tem como temática o paciente bariátrico e o uso do álcool. O interesse por este tema deu-se em decorrência do aumento do número de cirurgias bariátricas indicadas como estratégia ao combate da obesidade, vista complicações à saúde e qualidade de vida, atingindo crianças, adolescentes e adultos. O tratamento cirúrgico é oferecido a pacientes que apresentam obesidade mórbida, com insucesso em tratamentos anteriores e histórico de doenças crônicas agravadas pela obesidade. A questão norteadora do estudo refere-se: Seria o uso do álcool um dos dilemas enfrentados por pacientes pósoperados que se submeteram à intervenção cirúrgica bariátrica por meio de recomendação médica? Acredita-se que um dos dilemas enfrentados por pacientes que se submeteram à cirurgia bariátrica seja o uso abusivo do álcool, sendo comum, verificar o consumo exagerado de bebida alcóolica, compulsão por compras, sexo, trabalho, dentre outros, podendo acarretar a volta do desequilíbrio alimentar. Desta forma, deve-se dar maior atenção, tanto no período pré-operatório, quanto no pós-operatório da cirurgia bariátrica, perante tais constatações e devido ao aumento do número de cirurgias bariátricas como combate à obesidade. OBJETIVO: Verificar o consumo da bebida alcoólica em pacientes que intercorreram ao procedimento cirúrgico bariátrico e estão em acompanhamento psicológico MÉTODO: Estudo do tipo qualitativo transversal, de natureza descritiva e exploratória. O estudo envolveu pacientes atendidos no Centro de Tratamento Cirúrgico da Obesidade, envolvendo 16 pacientes que intercorreram a intervenção cirúrgica, selecionados de forma aleatória incluindo aqueles maiores de 18 anos, com mais de 7 meses de procedimento e o qual fez e/ou faz uso

\footnotetext{
${ }^{1}$ Acadêmica do curso de psicologia da Faculdade Patos de Minas - FPM. E-mail de contato: danielaportto@hotmail.com

${ }^{2}$ Mestre em Promoção da Saúde da Universidade de Franca - UNIFRAN - e docente do Departamento de Graduação em Psicologia da Faculdade Cidade Patos de Minas.
} 

de bebida alcóolica. Para tal, foi utilizado um roteiro de Entrevista sobre Estilo de vida e teste ASSIST e CAGE para verificar o envolvimento com o álcool. As entrevistas foram transcritas na íntegra e para aferição dos testes utilizou-se da padronização do instrumento. As análises qualitativas embasarão no método da hermenêutica dialética, e análise estatística serão descritivas exploratórias bivariada utilizando-se do auxílio do programa SPSS, versão 22. RESULTADOS: Foi registrado, no estudo realizado, a maior participação de mulheres e de solteiros na fase adulta. A intercorrência cirúrgica na maioria dos envolvidos ocorreram por indicação médica devido a questões de saúde como diabetes, problemas hepáticos, dores na articulação motivada pelo peso, colesterol e hipertensão. Verificou-se nos participantes a necessidade de adequação do corpo ao padrão estético, embora os danos de saúde devido ao sobrepeso, recebendo o apoio familiar para a intercorrência cirúrgico. Muitos demonstraram a tentativa de mudança de hábitos, no entanto, o insucesso nos resultados agia como facilitador para manter-se em hábitos não saudáveis. Em relação ao uso do álcool todos os envolvidos demonstraram consumir a bebida alcoólica, em alguns casos mais elevados após a intercorrência, evidenciando assim, para todos, a necessidade de receberem atenção especial para o consumo, e uma parcela a necessidade de cuidados intensivos a saúde por indicarem dependência da substância. DISCUSSÃO: Percebe-se que os envolvidos no estudo são em sua maioria mulheres, o que reflete a cultura ocidental, pautada na valorização do corpo magro como padrão de beleza. Apesar dos pacientes relatarem estarem preparados para a cirurgia, muitos desconhecem o processo pelo qual serão submetido e a real mudança que isso acarretará em sua vida Além de mudanças em seus hábitos, ocorrem muitas mudanças também no campo psíquico, por isso, a importância do acompanhamento psicológico durante todo o processo, auxiliando na perda e manutenção do peso, prevenindo e tratando possíveis alterações psíquicas advindas da mudança corporal, do comportamento e das relações sociais do paciente. Mesmo o estudo ter demonstrado que a maioria dos envolvidos procurou a cirurgia por indicação médica no intuito de melhorar seu estado de saúde, percebe-se também, por parte de alguns, a vontade de iniciar uma nova etapa em suas vidas e, principalmente, deixarem de sofrer discriminação social, vendo na cirurgia a possibilidade de resgatar a autoestima a muito tempo perdida. Percebe-se também, a importância do apoio familiar e dos parceiros para sucesso do tratamento. Apesar de muitos relatarem terem recebido esse apoio, nota-se a necessidade de maiores informações para que o grupo familiar se envolva e possa ajudar o paciente a modificar seus hábitos, ponto importante para que o processo seja bem-sucedido. Observa-se que, muitas vezes o paciente não estava preparado para tais mudanças, principalmente em relação ao alimento, com isso, passa a procurar por algo que irá suprir o vazio antes preenchido pelo ele. A bebida alcóolica, por ser de fácil ingestão, é muitas vezes utilizada para suprir as necessidades advindas da 

falta do alimento, além de possibilitar um convívio social sem gerar constrangimentos. Verificou-se através dos testes ASSIST e CAGE, utilizados nesse estudo, que todos os pacientes devem receber atenção especial quanto ao consumo abusivo do álcool e precisam receber intervenção breve para auxiliá-los nesse campo. Esse novo hábito pode trazer grandes problemas a esses pacientes, sendo importante considerar não apenas os efeitos do álcool em sua saúde, mas todas as consequências nocivas que o consumo pode provocar. CONSIDERAÇÕES FINAIS: Observou-se, através dos resultados encontrados no presente estudo, que o uso abusivo do álcool por pacientes bariátricos, trata-se de uma realidade. Percebe-se, que após a cirurgia, o paciente, em sua maioria, não se encontra preparado para enfrentar as mudanças em seu estilo de vida e ressignificar valores que o leve a superar problemas psicossociais. A busca pelo álcool se dá, muitas vezes, pela dificuldade de aderir a novos hábitos e apresenta como um artifício de fuga antes resolvido com o alimento, o que leva esse paciente a enfrentar novos problemas. Há necessidade de estudos mais aprofundados sobre o consumo de álcool por pacientes bariátricos, para que ocorra uma maior conscientização por parte dos profissionais envolvidos nesse processo, afim de rever ou afirmar que esse procedimento é eficaz e seguro para tratar a obesidade, reduzir as comorbidades e promover uma melhor qualidade de vida a esse paciente.

Palavras-chave: Cirurgia Bariátrica; Obesidade; Qualidade de Vida; Uso do álcool. 